\title{
A POSSIBLE CASE OF A NEWBORN PREMATURE BABY WITH LISTERIA MONOCYTOGENES INFECTION
}

\author{
Mirena Nikolova ${ }^{1}$, Tatina Todorova ${ }^{2}$, Gabriela Tsankova ${ }^{2}$, Neli Ermenlieva ${ }^{3}$ \\ ${ }^{1}$ Specialized Hospital of Obstetrics and Gynecology, Varna \\ ${ }^{2}$ Department of Preclinical and Clinical Sciences, Medical University of Varna \\ ${ }^{3}$ TRS "Medical Laboratory Assistant", Medical College, Medical University of Varna
}

\begin{abstract}
Listeria monocytogenes may cross and proliferate in the placenta and cause severe infections during pregnancy. In pregnant women, listeriosis usually occurs during the third trimester, when cell-mediated immunity is reduced. Common results are abortion, stillbirth, intrauterine and/or neonatal infections. The patient described here was a newborn male, delivered by emergency Cesarean section after chorioamnionitis in 33 weeks' gestation. Soon after the birth, the baby became high-oxygen-dose dependent with signs of pulmonary insufficiency. The blood tests showed decreased level of lung perfusion and ventilation, significant hypoxemia and hypercarbia. Listeria monocytogenes was isolated from ear secretion, while blood culture and other peripheral samples were negative. The baby was discharged on the 20th day of his birth with a weight of $2000 \mathrm{~g}$ and normal lung and heart function. On follow-up visits at the clinic, he showed normal neurological status, cognitive function and vital signs.
\end{abstract}

Keywords: Listeria monocytogenes, Listeriosis; Newborn health, Premature birth

\section{INTRODUCTION}

Listeria monocytogenes is an intracellular pathogenic bacterium with great importance in pregnancy and neonatal infections (1). It is widespread and after ingestion it can cross the placenta of pregnant women and cause severe amnionitis, spontaneous abortion, intrauterine fetal death or preterm birth (2). Neonates can be infected either in utero (re-

Address for correspondence:

Tatina Todorova

Medical University Varna

Faculty of Pharmacy

Department of Preclinical and Clinical Sciences

3, Bregalniza Str., 9002 Varna, Bulgaria

e-mail:Tatina.Todorova@mu-varna.bg

Received: January 21, 2016

Accepted: April 22, 2016 sulting in premature birth and early-onset infection) or during delivery (manifested as late-onset meningitis). Early-onset infection presents soon after birth with symptoms such as circulatory and respiratory insufficiency and sepsis, while late-onset meningitis occurs several days to weeks after the birth of apparently healthy full-term newborns. Although the neonatal listeriosis is a rare disease, the associated mortality ranges from 20 to $60 \%$ (3) and is higher in neonates with early-onset disease.

The current work reports a case of intraamniotic infection of a preterm newborn. Neonatal listeriosis is suggested as Listeria monocytogenes was isolated from the ear secretion of the newborn.

\section{CASE REPORT}

The patient was a premature male baby born to first-gravida mother diagnosed with chorioamnionitis (persisting febrile condition, leukocytosis, bleed- 
Mirena Nikolova, Tatina Todorova, Gabriela Tsankova et al.

ing and deteriorating fetal monitoring). Emergency Cesarean section was performed on June 2, 2013 (33 weeks' gestation) in a small private hospital in Varna. The Apgar score at the first and fifth minute after the birth was 6-7. Six hours later the newborn was transferred to the Specialized Hospital of Obstetrics and Gynecology, Varna with signs of fetal distress and pulmonary insufficiency.

The somatic and objective status of the baby was as follows: weight $-2000 \mathrm{~g}$; length $-47 \mathrm{~cm}$; head circumference - $31 \mathrm{~cm}$; skin - marmorated and pink; left conjunctiva - suppurative secretion. He was hypotonic with a weak reflex response. The breathing was shallow and not rhythmic with lots of crackles, while the heart function was normal with rhythmic and clear sounds. The examination of the abdominal status revealed normal and good peristalsis, canalized esophagus and no organomegalia.

On admittance in the neonatal intensive care unit, the baby was monitored and placed on oxygen supply. An intravenous infusion was started immediately. Biochemical tests showed high oxygen dependence, decreased lung perfusion and ventilation, as well as significant hypoxemia and hypercarbia. Detailed blood analyses are present in Table 1.

After admission, his pulmonary insufficiency deteriorated and the baby was intubated for 48 hours. The X-ray and transfontanelle ultrasonography examination revealed aspiration syndrome and cerebral oedema. Blood, peripheral secretions (nasal-throat, eye, ear and tracheal), gastric aspirate were sent for culture and identification of infectious agents. Gram-positive diphtheroid-like bacterium, defined as Listeria monocytogenes, was isolated from ear secretions, while blood and other samples were negative.
Empirical therapy with Sultamicillin (such as Unasyn) in $2 \times 80 \mathrm{mg} /$ day for 14 days, Amikacinsulphate (as Amikin) in $30 \mathrm{mg} /$ day for 14 days and Ceftriaxone (as Medaxone) in a dosage of $100 \mathrm{mg} /$ day for 5 days was started immediately. Two days later, the patient was extubated and passed the post-ventilation period without complications. Feeding was started and tolerated very well. Muscle tone, reflexes and breathing had significantly improved and the oxygen supply was stopped. Six days after admission the baby was transferred from the incubator to a bed.

The first dose of anti-hepatitis $B$ vaccine was administered but the anti-tuberculosis vaccine was postponed because of the low body weight.

The baby was discharged on the $20^{\text {th }}$ day of his birth - with a weight of $2000 \mathrm{~g}$ and normal lung and heart function. Normal and regular breast-feeding was started. On follow-up visits at the clinic, he showed normal neurological status, cognitive function and vital signs.

\section{CONCLUSION}

Early-onset neonatal listeriosis often results in severe septicemia and a fatal end for the newborn. In most of the European countries, the frequency of Listeria-caused infections varies between 0.1 and 11.3 per million population with $20 \%$ involving neonates (4). In Bulgaria, only six cases of listeriosis were registered by the National Surveillance System in 2015 (5). Here, we presented a case of neonatal infection. Listeria monocytogenes was isolated from the ear secretion of a preterm newborn suggesting a possible implication of this pathogen in the severe neonatal infection reported. According to the EU case definition, this case meets the relevant clinical and laboratory criteria for listeriosis in a newborn. However,

Table 1. Laboratory data during the clinical course

\begin{tabular}{|c|c|c|c|c|c|c|c|}
\hline No. & $\begin{array}{c}\operatorname{Hgb}(\mathrm{g} / \mathrm{l}) \\
\text { /ref. 120-180/ }\end{array}$ & $\begin{array}{c}\text { Hct (\%) } \\
\text { /ref. 35-45/ }\end{array}$ & $\begin{array}{c}\mathrm{RBC} \\
\left(\mathrm{x} 10^{12} / \mathrm{l}\right)\end{array}$ & $\begin{array}{c}\text { WBC }\left(\mathrm{x} 10^{9} / \mathrm{l}\right) \\
/ \text { ref. } 10-30 /\end{array}$ & $\begin{array}{l}\text { PLT }\left(x 10^{9} / 1\right) \\
\text { /ref.150-450/ }\end{array}$ & $\begin{array}{l}\text { CRP (mg/l) } \\
\text { /ref.0.1-5.4/ }\end{array}$ & $\begin{array}{l}\text { Blood sugar } \\
\text { (mmol/l) } \\
\text { /ref. 2.5-5.6/ }\end{array}$ \\
\hline 1 & 162 & 46 & 4.5 & 49.1 & 112 & 2.06 & 2.7 \\
\hline 2 & 142 & 42 & 4.1 & 48.7 & 219 & 7.27 & 3.1 \\
\hline 3 & 150 & 44 & 4.3 & 30.6 & 471 & 5.28 & 3.5 \\
\hline 4 & 152 & 42 & 4.8 & 23.5 & 543 & - & \\
\hline 5 & 157 & 45 & 4.7 & 20.6 & 580 & - & \\
\hline
\end{tabular}


we should state some points of criticism of the current work: despite the existing data for chorioamnionitis in the mother, the amniotic fluid sample was not microbiologically tested and Listeria was not isolated from a normally sterile site (blood or cerebrospinal fluid of the baby) to prove unambiguously listeriosis in the newborn.

\section{REFERENCES}

1. Southwick FS, Purich DL. Intracellular pathogenesis of listeriosis. N Engl J Med. 1996 Mar 21;334(12):770-6.

2. Maertens de Noordhout C, Devleesschauwer B, Angulo FJ, Verbeke G, Haagsma J, Kirk M, et al. The global burden of listeriosis: a systematic review and meta-analysis. Lancet Infect Dis. 2014 Nov;14(11):1073-82.

3. Lamont RF, Sobel J, Mazaki-Tovi S, Kusanovic JP, Vaisbuch E, Kim SK, et al. Listeriosis in human pregnancy: a systematic review. J Perinat Med. 2011 May;39(3):227-36.

4. Okike I, Lamont R, Heath PT. Do We Really Need to Worry About Listeria in Newborn Infants? Pediatr Infect Dis J. 2013;32(4):405-6.

5. NCPHP. http://ncphp.government.bg/ operativnainf/171-zar-zab.html [Internet]. 2015 [cited 2016 Jan 21]. Available from: http://ncphp. government.bg/operativnainf/171-zar-zab.html 